\title{
Minoxidil-Associated Pleuropericardial Effusion
}

\author{
Max Brondfield, $B A^{7}$, Lindsey Wu, MD'2, and Neal Benowitz, MD ${ }^{3}$ \\ 'University of California San Francisco School of Medicine, San Francisco, CA, USA; ${ }^{2}$ Department of Medicine, University of California San Francisco, \\ San Francisco, CA, USA; ${ }^{3}$ Departments of Medicine, Biopharmaceutical Sciences, Psychiatry, and Clinical Pharmacy, University of California San \\ Francisco, San Francisco, CA, USA; ${ }^{4}$ PGY3, Internal Medicine Residency, University of California San Francisco, San Francisco, CA, USA.
}

KEY WORDS: clinical image; case report; dialysis; pharmaceutical care; diagnosis.

J Gen Intern Med 31(9):1105

DOI: $10.1007 / \mathrm{s} 11606-016-3624-3$

(C) Society of General Internal Medicine 2016

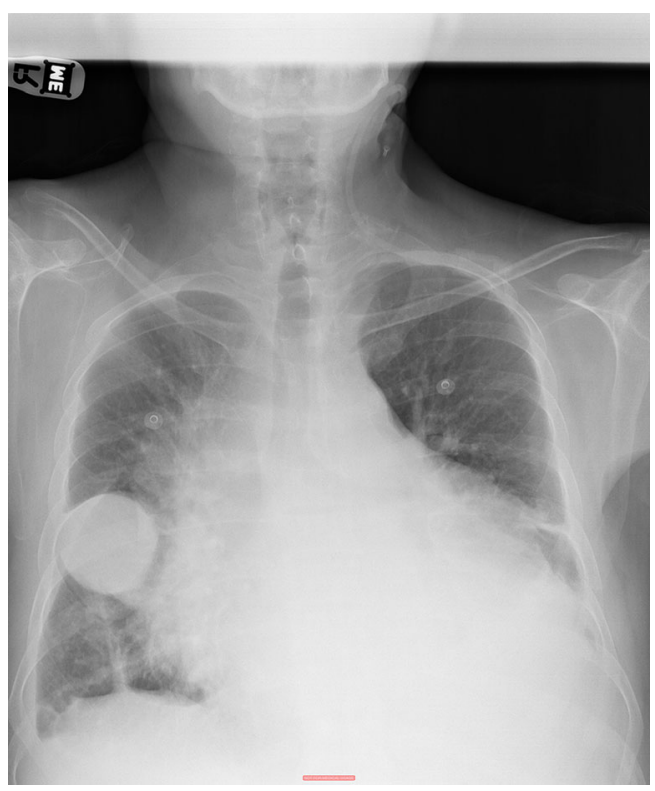

Figure 1. Posteroanterior (PA) chest X-ray with well-circumscribed opacity and enlarged cardiac silhouette.

A 53-year-old man with end-stage renal disease on hemodialysis presented with 3 weeks of exertional dyspnea. His medications included minoxidil, started 2 years prior for severe hypertension. Chest radiograph demonstrated markedly enlarged cardiac silhouette and a well-circumscribed opacity projecting over the right lung (Fig. 1). Chest computed tomography (CT) confirmed a large pseudotumor of pleural fluid and large pericardial effusion (Fig. 2). Pericardiocentesis removed $1.3 \mathrm{~L}$ of serosanguinous fluid, the analysis of which was nondiagnostic. Infectious, malignant, and rheumatologic causes were excluded, and the patient's adherence to dialysis made uremic pericarditis unlikely. Minoxidil toxicity was suspected. The drug was discontinued and within 1 week the patient returned to his baseline exercise tolerance with nearresolution of his pleuropericardial effusion on imaging.

Received July 20, 2015

Revised November 10, 2015

Accepted February 4, 2016

Published online March 7, 2016

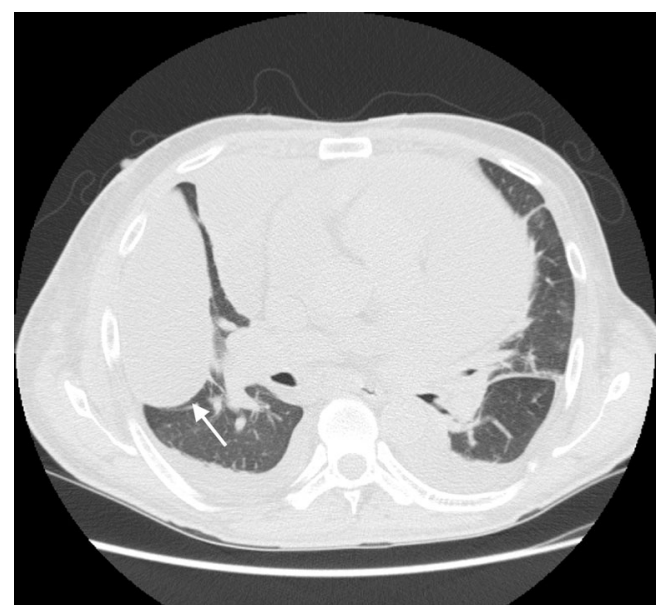

Figure 2. Computed tomography of the chest confirmed a large pseudotumor of loculated pleural fluid in the right lung.

Multiple case reports indicate that minoxidil use in dialysis patients can cause large volume pericardial effusions ${ }^{1}$; however, only three reports of minoxidilassociated pleural or pleuropericardial effusion have been published to date. ${ }^{2-4}$ In these cases, there were no recurrent effusions following cessation of the drug. In any patient on dialysis and minoxidil, identification of a pleural or pericardial effusion unresponsive to ultrafiltration should prompt suspicion of this complication.

Corresponding Author: Lindsey Wu, MD; PGY3, Internal Medicine ResidencyUniversity of California San Francisco, 505 Parnassus Ave, Room 987, San Francisco, CA 94143, USA (e-mail: lindsey.wu@ucsf.edu).

\section{Compliance with Ethical Standards:}

Conflict of Interest: The authors declare that they do not have a conflict of interest.

\section{REFERENCES}

1. Martin WB, Spodock DH, Zins GR. Pericardial disorders occurring during open-label study of 1,869 severely hypertensive patients treated with minoxidil. J Cardiovasc Pharmacol. 1980;2(2):S217-27.

2. Siddiqui A, Ansari M, Shakil J, Chemitiganti R. Minoxidil-associated exudative pleural effusion. South Med J. 2010;103(5):458-60.

3. Palomar R, Morales P, de Castro SS, et al. Pleural effusion secondary to minoxidil in a peritoneal dialysis patient. Nephrol Dial Transplant. 2004;19:2688.

4. Webb DB, Whale RJ. Pleuropericardial effusion associated with minoxidil administration. Postgrad Med J. 1982;58:319-20. 